\title{
Pengaruh Aromaterapi Lavender terhadap Percepatan Persalinan pada Ibu Primipara di RSUD Selebesolu Kota Sorong
}

\author{
Cory Situmorang ${ }^{1}$, Fredrika Nancy Losu ${ }^{2}$, Dian Pratiwi ${ }^{3}$ \\ ${ }^{1}$ jurusan Kebidanan Politeknik Kesehatan Kemenkes Sorong \\ 2,3jurusan Kebidanan Politeknik Kesehatan Kemenkes Manado \\ Email : losunancy@gmail.com
}

\begin{abstract}
ABSTRAK
Latar Belakang: Percepatan persalinan merupakan lamanya proses persalinan yang dimulai dari lahirnya bayi sampai dengan lahirnya plasenta. Salah satu cara yang berpengaruh terhadap percepatan persalinan pada ibu primipara yaitu Pemberian Aromaterapi Lavender.

Tujuan: mengetahui pengaruh Aromaterapi Lavender Terhadap Percepatan Persalinan pada Ibu Primipara di RSUD Sele Be Solu Kota Sorong.

Metode: Jenis penelitian ini menggunakan desain quasi experiment dengan rancangan nonequivalent control group design.

Hasil: Hasil penelitian pada kelompok intervensi dan kelompok kontrol pada Kala I diberikan Aromaterapi Lavender terhadap percepatan persalinan pada ibu primipara dan uji statistic dengan Mann Whitney maka didapatkan ha diterima dimana nilai p $0,016<0,05$, Analisis data dan hasil penelitian kelompok intervensi dan kelompok control pada Kala II diberikan Aromaterapi Lavender terhadap percepatan persalinan pada ibu primipara yang dibuktikan dengan hasil uji statistic menggunakan Mann Whitney didapatkan nilai $\mathrm{p} 0,030<0,05$.

Kesimpulan: Terdapat pengaruh Aromaterapi Lavender terhadap percepatan persalinan pada ibu primipara. Rekomendasi pemberian aromaterapi lavender dapat diberikanan pada pasien bersalin.
\end{abstract}

Kata kunci : Aromaterapi Lavender; Percepatan Persalinan; Primipara

\begin{abstract}
Background : The acceleration of childbirth is the length of the labor process that starts from the birth of the baby to the birth of the placenta. One of the ways that affect the acceleration of childbirth in primipara mothers is lavender aromatherapy.

Purpose : knowing the effect of Lavender Aromatherapy on The Acceleration of Childbirth on Primipara Mothers at Sele Be Solu Hospital in Sorong City.

Method: This type of research uses a quasi-experiment design with nonequivalent control group design. Results : The results of studies in the intervention group and control group in Kala I were given Lavender Aromatherapy against the acceleration of childbirth in primipara mothers and statistical tests with Mann Whitney then obtained ha received where the value of $p$-value $0.016<0.05$, Analysis of data and results of intervention group studies and control group in Kala II administered Lavender Aromatherapy to the acceleration of childbirth in primipara mothers as evidenced by statistical test results using Mann Whitney obtained a value of p-value of 0.030 .

Conclusion : There is an influence of Lavender Aromatherapy on the acceleration of childbirth in primipara mothers. Recommendations for aromatherapy of lavender can be given to maternity patients.
\end{abstract}

Keywords: Aromatherapy Lavender; Acceleration of Childbirth; Primipara

\section{PENDAHULUAN}

Nyeri persalinan mengakibatkan rasatakut dan stres. Stres pada ibu akan menyebabkan pengeluaran hormon stres

seperti katekolamin dan steroid sehingga mengakibatkan pengurangan aliran darah ibu ke janin. (1) Untuk mengurangi efek 
stres fisiologis maupun psikologis akibat nyeri persalinan dapat dilakukan melalui penanganan nonfarmakologi dengan cara penghirupan aromaterapi lavender, karena tidak memberikan efek invasif tetapi aman bagi ibu maupun bayi ${ }^{(2)}$, karena menurut penelitian terdahulu oleh Lis-Balchin (2009), kandungan lavender oil yang terdiri dari: linalool, linalyl acetate, $\alpha$ - dan $\beta$ pinene dan 1,8- cineole dapat menurunkan secara spontan kontraksi uterus pada tikus yang sedang mengalami spasme pada otot intestinalnya. ${ }^{(3)}$

Nyeri persalinan yang timbul semakin sering dan semakin lama dapat menyebebkan ibu gelisah, takut dan tegang bahkan stress yang berakibat pelepasan hormone yang berlebihan seperti adrenalin, katekolamin, dan stroid.Hormone ini dapat menyebabkan terjadinya ketegangan otot polos dan vasokontriksi pembuluh darah yang berakibat berkurangnya aliran darah dan oksigen ke uterus sehingga dapat menyebabkan terjadinya iskemia uterus, hipoksia janin dan membuat implus nyeri bertambah banyak. Meningkatnya katekolamin dapat menyebabkan gangguan padakekuatan kontraksi uterus sehingga terjadi inersia uteri yang berdampak pada partus lama.

Saat ini proses persalinan pervaginam telah berkembang, bertujuan memberi rasa nyaman, aman dan menyenangkan, serta dapat mengurangi dan bila mungkin meniadakan rasa cemas dan menegangkan. Ada beberapa metode nonfarmakologis yang dapat diterapkan dalam mengurangi nyeri persalinan, salah satunya adalah dengan aromaterapi.

Aromaterapi adalah terapi komplementer dalam praktek keperawatan dan menggunakan minyak esensial dari bau harum tumbuhan untuk mengurangi masalah kesehatan dan memperbaiki kualitas hidup. Teori mengatakan bahwa bau berpengaruh secara langsung terhadap otak seperti obat analgesik. Misalnya, mencium lavender maka akan meningkatkan gelombang-gelombang alfa didalam otak dan membantu untuk merasa rileks. ${ }^{(4)}$

Aromaterapi lavender merupakan tindakan terapeutik yang bermanfaat meningkatkan kondisi fisik dan psikologis ibu bersalin.Secara fisik baik digunakan untuk mengurangi rasa nyeri, sedangkan secara psikologis dapat merilekskan pikiran, menurunkan ketegangan dan kecemasan serta memberi ketenangan. Menurut penelitian sebelumnya tentang pengaruh pemberian aromaterapi lavender menyatakan, bau yang menyenangkan akan menimbulkan perasaan tenang, dan senang yang dapat mengurangi kecemasan. Aromaterapi dari limbik menstimulasi sekresi enkefalin atau endorfin di hipotalamus, PAG (Periaqueductal Grey), dan medula rostral ventromedial. Daerah otak yang disebut, raphe nucleus yang akan terstimulus untuk mengeluarkan serotonin sehingga menimbulkan efek rileks, tenang dan menurunkan kecemasan. ${ }^{(5)}$

Hal ini menyebabkan tidak dapat diteruskannya ke proses yang lebih tinggi, di kortek somatosensoris dan transisional. Hal ini disebabkan karena lavender merupakan minyak essensial analgesik yang mengandung $8 \%$ terpena, $6 \%$ keton yang mempunyai efek sedatif, lavender juga mengandung 30-50\% linalil asetat yang merupakan senyawa ester yang dapat menormalkan keadaan emosi serta keadaan tubuh yang tidak seimbang, dan juga 
memiliki khasiat sebagai penenang serta tonikum, khususnya pada sistem saraf.

Berdasarkan survey awal yang dilakukan oleh peneliti pada bulan Pebruari 2019 di RSUD Sele Be Solu Kota Sorong maka didapatkan data 10 bulan terakhir yang terdiri dari data ibu bersalin primipara normal kurang lebih terdapat $30 \mathrm{ibu}$ bersalin primipara normal setiap bulannya. Dari 30 ibu bersalin tersebut terdapat sebagian kecil ibu bersalin yang mengalami persalinan Kala I macet dan persalinan Kala II lama. Penelitian ini bertujuan untuk mengetahui adanya pengaruh aromaterapi lavender terhadap percepatan persalinan pada ibu primipara.

\section{METODE}

\section{HASIL}

1. Data Umum Responden

Tabel 1 Distribusi frekuensi berdasarkan usia, kunjungan ANC dan pekerjaan responden

\begin{tabular}{ccc}
\hline Karakteristik Responden & $\mathrm{f}$ & $\%$ \\
\hline Usia : Resiko tinggi & 3 & 10 \\
Resiko rendah & 27 & 9 \\
Kunjungan ANC : Rutin & 18 & 60 \\
Tidak Rutin & 12 & 40 \\
Pekerjaan : Tidak Bekerja & 24 & 20 \\
Bekerja & 6 & 8 \\
\end{tabular}

Berdasarkan table 1 menunjukkan bahwa sebagian besar responden termasuk dalam usia resiko rendah (90\%). Responden yang melakukan kunjungan ANC rutin $(60 \%)$ dan sebagian kecil responden tidak
Jenis peneliti menggunakan desain quasi experiment yaitu dengan menggunakan rancangan penelitian None quivalent Control Group Design. Populasi dalam penelitian ini yaitu seluruh ibu hamil pertama normal di RSUD Selebesolu Kota Sorong sebanyak 30 responden. Teknik sampling yang digunakan adalah sampling Jenuh. Kriteria inklusi dalam penelitian ini yaitu Ibu bersalin pertama secara normal, Ibu bersalin dengan psikologis normal, Ibu bersalin dengan janin tunggal. Instrumen yang digunakan dalam penelitian ini adalah Diffuser dan Aromaterapi Lavender dan partograf. Cara kerja instrument yaitu pasien menghirup aromaterapi yang keluar dari alat diffuser.

\section{Data Khusus}

melakukan kunjungan ANC dengan rutin (40\%). Sebagian besar responden yang tidak bekerja $(80 \%)$ dan sebagian kecil responden yang bekerja (20\%).

Tabel 2. Percepatan persalinan kala I

\begin{tabular}{lcccc}
\hline \multirow{2}{*}{ Kelompok } & \multicolumn{4}{c}{ Percepatan Persalinan } \\
\cline { 2 - 5 } & \multicolumn{3}{c}{ Lama } & \multicolumn{3}{c}{ Cepat } \\
\cline { 2 - 5 } & $\mathrm{f}$ & $\%$ & $\mathrm{f}$ & $\%$ \\
\hline Kala I & & & 12 & 80 \\
$\quad$ Intervensi & 3 & 20 & 4 & 26,6 \\
$\quad$ Kontrol & 11 & 73,4 & 43,4 \\
Kala II & & & & \\
$\quad$ Intervensi & 4 & 26,6 & 11 & 73,4 \\
$\quad$ Kontrol & 12 & 80 & 3 & 20 \\
\hline
\end{tabular}

Volume 7 Nomor 1. Juli-Desember 2019 
Berdasarkan tabel 2 dapat dilihat bahwa saat persalinan kala I pada kelompok intervensi paling banyak mengalami persalinan cepat yaitu 12 orang (80\%) dibandingkn persalinan lama yaitu 3 orang (20\%), sedangkan pada kelompok kontrol paling banyak mengalami persalinan lama yaitu 11 orang $(73,4 \%)$ dari pada persalinan cepat yaitu 4 orang $(26,6 \%)$. Saat persalinan kala II pada kelompok intervensi paling banyak mengalami persalinan cepat yaitu 11 orang $(73,4 \%)$ dari pada persalinan lama yaitu 4 orang $(26,6 \%)$, sedangkan pada kelompok kontrolpaling banyak mengalami persalinan lama yaitu 12 orang (80\%) dibandingkn persalinan cepat yaitu 3 orang (20\%).

\section{Pengaruh Aromaterapi Lavender terhadap percepatan persalinan kala I dan kala II pada kelompok Intervensi dan Kontro}

Tabel 3. Pengaruh Aromaterapi Lavender terhadap percepatan persalinan kala I dan kala II pada kelompok Intervensi dan kelompok control

\begin{tabular}{lcc}
\hline Percepatan persalinan & Rata-rata & P \\
\hline Intervensi & & \\
$\quad$ Kala I & 11,60 & 0,016 \\
$\quad$ Kala II & 64,00 & 0,030 \\
Kontrol & & \\
Kala I & 13,73 & 0,016 \\
Kala II & 84,00 & 0,030 \\
\hline
\end{tabular}

Berdasarkan tabel 3 dapat Percepatan persalinan kala I pada kelompok disimpulkan bahwa percepatan persalinan kontrol mempunyai nilai rata-rata yaitu 13,73 kala I pada kelompok intervensi mempunyai jam dan mempunyai nilai $\mathrm{p}$ 0,016 sedangkan nilai rata-rata yaitu 11,60 jam dan percepatan persalinan kala II pada kelompok mempunyai nilai p 0,016 sedangkan kontrol mempunyai nilai rata-rata 84,00 percepatan persalinan kala II pada kelompok intervensi mempunyai nilai rata-rata 64,00 menit dan mempunyai nilai $p \quad 0,030$. menit dan mempunyai nilai p 0,030.

\section{Analisis Bivariate}

Tabel 4 Hasil Uji Mann Whitney Kala I dan Kala II

\begin{tabular}{lcccc}
\hline Kelompok & Maksimum & Minimum & Mean & p \\
\hline Kala I & & & & \\
$\quad$ Intervensi & 16 & 9 & 11,60 & 0,016 \\
$\quad$ Kontrol & 16 & 10 & 13,7 & \\
Kala II & & & & 0,030 \\
$\quad$ Intervensi & 100 & 30 & 64,00 & \\
$\quad$ Kontrol & 100 & 40 & 84,00 & \\
\hline
\end{tabular}

Berdasarkan tabel 4 dapat dilihat bahwa rerata waktu persalinan Kala I pada kelompok intervensi lebih cepat yaitu 11,6 jam daripada rerata lama persalinan pada kelompok kontrol yaitu 13,7 jam. Analisis data dan hasil penelitian kelompok intervensi dan kelompok kontrolpada Kala I diberikan Aromaterapi Lavender terhadap percepatan 
persalinan pada ibu primipara dan kemudian dilakukan uji statistic dengan Mann Whitney didapatkan nilai p 0,016<0,05 maka dapat disimpulkan bahwa terdapat pengaruh Aromaterapi Lavender terhadap percepatan persalinan pada ibu primipara di RSUD Kota Sorong.

Rerata waktu persalinan Kala II pada kelompok intervensi lebih cepat yaitu 64,00 menit daripada rerata lama persalinan pada kelompok kontrol yaitu 84,00 menit. Analisis data dan hasil penelitian kelompok intervensi dan kelompok control pada Kala II diberikan Aromaterapi Lavender terhadap percepatan persalinan pada ibu primipara dan kemudian dilakukan uji statistic dengan Mann Whitney didapatkan nilai p $0,030<0,05$ maka dapat disimpulkan bahwa terdapat pengaruh Aromaterapi Lavender terhadap percepatan persalinan pada ibu primipara di RSUD Kota Sorong.

\section{PEMBAHASAN}

Hasil uji statistik yang telah di lakukan, ibu yang mengalami persalinan cepat pada kelompok intervensi kala I berjumlah 12 orang $(80 \%)$ sedangkan ibu yang mengalami persalinan lama pada kelompok intervensi kala I berjumlah 3 orang (20\%). Ibu yang mengalami persalinan cepat pada kelompok intervensi kala II berjumlah 11 orang $(73,4 \%)$ sedangkan ibu yang mengalami persalinan lama pada kelompok intervensi kala II berjumlah 4 orang (26,6\%).Ibu yang mengalami persalinan cepat pada kelompok kontrol kala I berjumlah 4 orang $(26,6 \%)$ sedangkan ibu yang mengalami persalinan lama pada kelompok kontrol kala I berjumlah 11 orang $(73,4 \%)$. Ibu yang mengalami persalinan cepat pada kelompok kontrol kala II berjumlah 3 orang (20\%) sedangkan ibu yang mengalami persalinan lama pada kelompok kontrol kala II berjumlah 12 orang (80\%).

Hasil penelitian ini menunjukan bahwa Aromaterapi Lavender efektif untuk percepatan persalinan pada Kala I dengan nilai p 0,016 dan pada Kala II dengan nilai $\mathrm{p}$ 0,030 penelitian ini juga berhubungan dengan intensitan nyeri sejalan dengan hasil penelitian yang menunjukkan bahwa terdapat hubungan antara Aromaterapi Lavender dengan intensitas nyeri. ${ }^{(5)}$

Berdasarkan hasil penelitian karakteristik usia wanita yang terlalu muda dan terlalu tua dapat mengeluhkan tingkat percepatan persalinan yang berbeda dan meningkatnya usia maka toleransi percepatan persalinan semakin meningkat pula. Selain itu, teori menyatakan bahwa usia berhubungan secara langsung dengan percepatan persalinan karena mempengaruhi emosi seseorang dan berpengaruh pada harapan selama perawatan persalinan. Sehingga dalam penelitian ini rentang usia yang dipilih yaitu usia 20-35 tahun. Hal ini sesuai dengan teori bahwa ibu yang berusia 20-35 tahun secara fisik dan psikologis sudah siap dalam menghadapi kehamilan dan persalinan. $^{(6)}$

Pendidikan terakhir responden tidak berpengaruh terhadap percepatan persalinan dalam penelitian ini. Hasil ini sesuai dengan penelitian yang menyatakan bahwa karakteristik pendidikan tidak berpengaruh terhadap percepatan persalinan karena ibu yang berpendidikan belum tentu memiliki pengetahuan yang baik dan begitupun sebaliknya. Selain itu, dalam penelitian ini peneliti memberikan edukasi singkat kepada setiap responden tentang percepatan persalinan dan proses persalinan sehingga responden memiliki pengetahuan dan persepsi yang sama tentang percepatan 
persalinan agar dapat meminimalkan resiko karena faktor pendidikan. ${ }^{(7)(8)}$

Penelitian lain yang mendukung yaitu bertujuan mendeskripsikan manfaat aromaterapi lavender terhadap penurunan nyeri persalinan ibu pada kala I fase aktif. Kemudian sampel yang digunakan tidak membedakan antara paritas rendah dan tinggi sehingga tidak membedakan antara persepsi nyeri pada primigravida dan multigravida. Umumnya primipara merasakan nyeri lebih lama dan lebih sakit daripada multipara karena primipara membutuhkan peregangan serviks yang lebih kuat sebab belum pernah terjadi peregangan. Hal ini menyebabakan kontraksi kala I lebih kuat pada primipara. ${ }^{(9)}$

Menurut peneliti yang telah melakukan penelitian di RSUD Sele Be Solu Kota Sorong pemberian aromaterapi lavender yang bermanfaat meningkatkan kondisi fisik dan psikologis ibu saat bersalin. Secara fisik baik digunakan untuk mengurangi rasa nyeri, sedangkan secara psikologis dapat merilekskan pikiran, menurunkan ketegangan dan kecemasan serta memberi ketenangan pada ibu agar saat proses persalinan ibu mempunyai tenaga untuk mengedan. Teori mengatakan bahwa bau berpengaruh secara langsung terhadap otak seperti obat analgesik. Misalnya, mencium lavender maka akan meningkatkan gelombang-gelombang alfa didalam otak dan membantu untuk merasa rileks. ${ }^{(4)}$

Beberapa penelitian telah menunjukkan bahwa lavender efektif dijadikan aromaterapi, seperti pada hasil penelitian yang menunjukkan bahwa ada perbedaan antara skala nyeri sebelum dan sesudah pemberian terapi aroma lavender pada klien infark miokard, (10) dan hasil penelitian sebelumnya menunjukkan ada perbedaan nyeri sebelum dan sesudah pemberian aromaterapi lavender pada ibu post section Caesar di RSUD Ambarawa. ${ }^{(11)}$

Aromaterapi lavender juga menurunkan tingkat kecemasan pada pasien sebelum operasi dengan anestesi spinal di RS Tugu Semarang. ${ }^{(12)}$

\section{KESIMPULAN}

Aromaterapi Lavender efektif dalam percepatan persalinan dengan nilai $p 0,016<$ 0,05 dan pada Kala II di dapatkan nilai $\mathrm{p}$ $0,030<0,05$

\section{DAFTAR PUSTAKA}

1. Susilarini S, Winarsih S, Idhayanti RI. Pengaruh pemberian aromaterapi lavender terhadap pengendalian nyeri persalinan kala i pada ibu bersalin. J Kebidanan. 2017;6(12).

2. Tarsikah, Susanto H, Sastramihardja HS. Penurunan Nyeri Persalinan Primigravida Kala I Fase Aktif Pascapenghirupan Aromaterapi Lavender. Maj Kedokt Bandung. 2012;44(1).

3. Lis-Balchim M. Aromatheraphy science a guide for healthcare profesionals. London: Pharmaceutical Pres; 2009.

4. Sharma S. Aroma Terapi. Tangerang: Karisma; 2009.

5. Karlina S, Reksohusodo S, Widayati A. The Influence of Lavender Aromatherapy Inhalation to Relieve Physiological Labor Pain Intensity i n Primipara Inpartu Active Phase in BPM "Fetty Fathiyah" Mataram City. Fak Kedokt Univ Brawijaya. 2014;108-19.

6. Manuaba, IBG. Penyakit Kandungan dan KB Untuk Pendidikan Bidan. In: Ilmu Kebidanan. 2014.

7. Budiastutik I, Rahfiludin MZ. Faktor Risiko Stunting pada anak di Negara Berkembang. merta Nutr. 2019;122-6.

Volume 7 Nomor 1. Juli-Desember 2019

Corry $S$, et al.............Pengaruh Aroma terapi lavender.... 
8. Sulistyowati DID. Efektifitas terapi aroma lavender terhadap tingkat nyeri dan kecemasan persalinan primipara kala I di rumah sakit dan Klinik Bersalin Purwokerto. Universitas Indonesia; 2009.

9. Kumalasari EP. Studi Tentang Manfaat Aromaterapi (Aroma Lavender) Terhadap Penurunan Tingkat Nyeri Ibu Pada Persalinan Kala I Fase Aktif di Bidan Praktek Swasta Wilayah Kerja Puskesmas Ngletih Kecamatan Pesantren Kota Kediri. Sekolah Tinggi Ilmu Kesehatan Surya Mitra Husada.; 2012.

10. Dasna, Utami GT, Arneliwati. Efektifitas Terapi Aroma Bunga Lavender (Lavandula Angustifolia) terhadap Penurunan Skala Nyeri pada Klien Infark Miokard. J Online Mhs Bid Ilmu Keperawatan. 2015;2(1):612-9.

11. Swandari P. Perbedaan Tingkat Nyeri Sebelum dan Sesudah Pemberian Aromatherapi Lavender pada Ibu Post Sectio Caesarea di RSUD Ambarawa [Internet]. Diploma IV Kebidanan STIKES Ngudi Waluyo Ungaran; 2014. Available from: https://docplayer.info/43308531-Perbedaantingkat-nyeri-sebelum-dan-sesudah-pemberian-aromatherapi-lavender-pada-ibu-post-sectiocaesarea-di-rsud-ambarawa.html

12. Arwani, Sriningsih L, Hartono R. Pengaruh Pemberian Aromaterapi Terhadap Tingkat Kecemasan Pasien Sebelum Operasi dengan Anastesi Spinal di RS Tugu Semarang. J Keperawatan Jiwa. 2013;1(2):129-34. 
